Recepción: 02/05/16

Evaluación: 05/05/16

Aprobación: 28/06/16

Artículo de Investigación Científica

\title{
LA ESCUELA TELEDIRIGIDA O EDUCACIÓN 2.0. UNA REFLEXIÓN EN CONTRA DEL REBAÑO DIGITAL
}

\author{
Carlos Geovanny Campiño Rojas* \\ Universidad de Baja California - México \\ Grupo de Investigación: Educación y postmodernidad \\ carlosgeovannycr@hotmail.com
}

\begin{abstract}
RESUMEN
"La escuela teledirigida o educación 2.0. Una reflexión en contra del rebaño digital" es el resultado de una investigación minuciosa centrada alrededor de la órbita del fenómeno posmoderno y su aliado estratégico, conocido con el nombre de "era de la información".

En este orden de ideas, y amparados bajo el insumo de la pedagogía crítica, se pretenden evidenciar los objetos de seducción y demanda que maquinan al interior de la anatomía y arquitectura educativa postmoderna; parcialidad Colombia, empeñada actualmente en alienar, desmantelar y configurar la subjetividad de docentes y estudiantes desde influjos contraculturales cargados de hibridación cultural, imperio efímero de la moda, cultura digital y capitalismo cognitivo.

En consecuencia, se espera armar un plan de contingencia capaz de contrarrestar los señuelos ideológicos que han penetrado con fuerza en la urdimbre educativa, a tal punto de inaugurar nuevas lógicas de poder, empotradas en la arista de la era de la información, quien amenaza con reducir sistemáticamente a los establecimientos educativos latinoamericanos a la mera consideración de pequeños relatos de naturaleza líquida y flotante, condenados a una potencial vía de extinción.

Orientadas bajo la brújula de la metamorfosis educativa, se pretende, finalmente, dar respuesta al malestar digital presente, así como preparar a la comunidad educativa para contrarrestar su intensidad y transformar la realidad social de los contextos vulnerables a su accionar.
\end{abstract}

Palabras clave: Aldea global, postmodernidad, cultura digital, homo tecnologicus, globalización, pedagogía crítica, cibercultura, E-learning, capitalismo cognitivo.

* Candidato a Doctor en Educación, Universidad de Baja California-México. Presidente de la Fundación Gabriel García Márquez de Pupiales, Nariño, Colombia. Catedrático Etnoliterario del gran pueblo de los Pastos Nariño-Colombia. 


\title{
THE REMOTE SCHOOL OR 2.0 EDUCATION REFLECTION AGAINST THE DIGITAL HERD
}

\begin{abstract}
"The Remote Control School or 2.0 Education. A reflection against the digital herd "is the result of a detailed research centered around the postmodern phenomenon and its strategic allied, known as the" information age."

In this order of ideas, and protected under the input of critical pedagogy, we intended to evidence the objects of seduction and demand that they are machined within the postmodern anatomy and educational architecture; partiality Colombia, currently committed to alienating, dismantling and configuring the subjectivity of teachers and students from counterculture influences loaded with cultural hybridization, ephemeral empire of fashion, digital culture and cognitive capitalism.

Consequently, a contingency plan is expected to counteract the ideological lures that have penetrated strongly in the educational warp, to the point of creating new logics of power, embedded in the edge of the information age, which threatens to systematically reduce educational establishments in Latin America to the mere consideration of small stories of a liquid and floating nature, condemned to a potential extinction route.

Guided by the compass of the educational metamorphosis, it is intended, finally, to respond to the current digital malaise, as well as to prepare the educational community to counteract its intensity and transform the social reality of the contexts vulnerable to its action.
\end{abstract}

Keywords: Global village, postmodernity, digital culture, homo tecnologicus, globalization, critical pedagogy, cyberculture, E-learning, cognitive capitalism.

\section{A ESCOLA TELEDIRIGIDA OU EDUCAÇÃO 2.0.UMA REFLEXÃO CONTRA O REBANHO DIGITAL}

\begin{abstract}
RESUMO
"A Escola de Controle Remoto ou Educação 2.0. Uma reflexão contra o rebanho digital "é o resultado de pesquisa meticulosa centrada em torno da órbita do fenômeno pós-moderno e seu aliado estratégico, conhecido como" era da informação ".

Nesta ordem de ideias e protegidas sob a influência da pedagogia crítica, pretendem evidenciar os objetos de sedução e demanda que são usinados dentro da anatomia pós-moderna e arquitetura educacional; Parcialidade, a Colômbia, atualmente comprometida em alienar, desmantelar e configurar a subjetividade de professores e estudantes de influências de contracultura carregadas de hibridização cultural, império efêmero da moda, cultura digital e capitalismo cognitivo.

Conseqüentemente, espera-se que um plano de contingência seja capaz de contrariar as atrações ideológicas que penetraram fortemente na urdimbre educacional, até o ponto de inaugurar novas lógicas de poder, incorporadas à
\end{abstract}


beira da era da informação, que ameaçam para reduzir sistematicamente os estabelecimentos educacionais na América Latina para a mera consideração de pequenas histórias de natureza líquida e flutuante, condenadas a uma possível rota de extinção.

Guiados pela bússola da metamorfose educacional, pretende-se, finalmente, responder ao mal-estar digital atual, bem como preparar a comunidade educacional para contrariar sua intensidade e transformar a realidade social dos contextos vulneráveis à sua ação.

Palavras-chave: aldeia global, pós-modernidade, cultura digital, homo tecnologicus, globalização, pedagogia crítica, cibercultura, e-learning, capitalismo cognitivo.

\section{INTRODUCCIÓN}

Nos encontramos hoy ante una latente bifurcación de caminos, que demarcan dos destinos: por un lado, un mundo cambiante, inserto en lo que muchos llaman posmodernidad; por otro, una escuela fragmentada, producto de la realidad histórica de la modernidad tardía. Parece haber una especie de grieta entre los procesos de formación inicial de docentes y las demandas sociales que suscita el volátil mundo postmoderno, empeñado cada vez más en sacudir la estructura base de la educación desde su excéntrico fenómeno de inmanentismo e indiferencia relajada, ahora camuflada en el señuelo de cultura digital.

Diversidad versus homogeneidad, inmediatez versus reflexión, incertidumbre versus certeza, identidad versus hibridación, imagen versus texto, inteligencia artificial versus vida orgánica, etc., son tan solo algunos ejemplos que atisban con fuerza el fenómeno educativo posmoderno. A la escuela actual se le exige re-fundarse, re-significarse, acomodarse a esta paradójica lógica que arrastra consigo el espectro postmoderno, que ratifica el ideario de allanar y desmantelar el acontecimiento educativo desde un sigiloso ataque neoliberal propinado directamente al cerebro de la escuela.

\section{LAS OPCIONES EDUCATIVAS}

Con este panorama sombrío, emergen vertiginosamente opciones educativas engañosas que promueven contratos inestables, profesores temporales y polivalentes, sobrecarga laboral, carreras virtuales, salarios injustos, escasa participación de la comunidad universitaria en la toma de decisiones, coerción del pensamiento, etc., flagelos académicos que dilatan en profundidad la actual crisis educativa, todo ello producto de la transposición semántica de conceptos provenientes de la administración de empresa, que comienzan a migrar con fuerza a la anatomía educativa, para convertir a los establecimientos educativos no solo en multinacionales de servicios, sino, además, en rebaños digitales, cifras y algoritmos, como ha venido ocurriendo durante las últimas décadas, cuando el 
neoliberalismo, junto con la era de la información, fueron tomando por asalto cada una de las dimensiones de la vida.

En consecuencia, el mandato histórico que otrora caracterizó a las escuelas y docentes, como agentes de difusión de la cultura letrada, está hoy en un aprieto y en un prolongado debate. Están en cuestión, por tanto, los significados y sentidos de las instituciones educativas del siglo XXI, el concepto de objetividad y de historia; por ende, el acto educativo en su complejidad, que se debate en un duelo irresuelto de identidad, al tratar de pintar su rostro somnoliento con brochazos contraculturales untados de "hibridación cultural", principio de incertidumbre, globalización, Tratados de Libre Comercio y cultura digital, encargados de inaugurar las nuevas guerras tecnológicas y de conocimiento.

Sin embargo, en las paradojas de la postmodernidad no solo la educación es líquida, sino, también, sus culturas; una especie de humedales de la información, que circulan por las cañerías de las mega-ciudades, de cuyas cloacas se expelen aromas residuales de sociedades cosméticas, maquilladas en el tocador de la industria artificial y, peor aún, incubadas en el seno mismo de la era de la información, a la que se le ha encomendado la tarea de instrumentalizar el pensamiento y reducir al sujeto a la condición de ordenador o paquete de software que circula en los mercados libres, que templan las pasarelas de la sociedad de consumo. El mundo se oscurece, se aletarga paulatinamente y, en los países latinoamericanos, marcados por el estigma del posconflicto, como ha sido el caso colombiano, la única luz que se ve a diario es la producida por las pantallas de celulares o de televisión y la que producen las armas de fuego. Ante tal desazón, la educación parece haber invertido sus lógicas y sucumbir sin resistencia ante el hechizo del imperio efímero de la moda, que promulga la cultura del "todo vale", independientemente de su valor. Por ello, lo pre-moderno ha cedido paso a lo postmoderno, la palabra al ciberespacio, la ciencia a la pseudo-ciencia y la tradición oral a las web-cámaras que vigilan y castigan.

En efecto, el paradigma educativo se ha desajustado considerablemente y la figura presencial del docente se expone a una potencial vía de extinción, insuflada por la seducción de las "máquinas de visión" que configuran al sujeto desde su neuromercadeo, que afecta considerablemente los contextos latinoamericanos, ahora amedrentados por el talante de la postmodernidad, que ha establecido el dominio de la imagen sobre la escritura, de la información ligera y distorsionada sobre la reflexión, para imponerse, en última instancia, como un poder mediáticoeconómico, de corte profundamente anti-educativo y anti-subjetivo. Este nuevo orden económico mundial, sustentado en las premisas de la nueva era (New Age), expresa su hegemonía en todas las esferas sociales que hilvanan la cultura, en las cuales es posible entrever una educación matizada por las corporaciones multinacionales, que convierten al mismo tiempo al Sistema educativo en parte del mundo de los negocios, del que es posible obtener beneficios económicos inmensurables. 
Hoy vivimos simultáneamente en dos mundos paralelos y diferentes. Uno, creado por la tecnología online, que nos permite transcurrir horas frente a una pantalla. Por otro lado, tenemos una vida normal. La otra mitad del día consciente la pasamos en el mundo que, en oposición al mundo online, llamo offline. (...) Estamos en proceso de liquidez ayudada por el desarrollo de esta tecnología. Estamos olvidando lentamente, o nunca lo hemos aprendido, el arte del diálogo. Entre los daños más analizados y teóricamente más nocivos de la vida online están la dispersión de la atención, el deterioro de la capacidad de escuchar y de la facultad de comprender, que llevan al empobrecimiento de la capacidad de dialogar, una forma de comunicación de vital importancia en el mundo offline.

Zygmunt Bauman

El basurero informático — sutilmente llamado ciberespacio- ofrece, cada vez más, un menú variado de opciones de reciclaje, que van desde el famoso "copie y pegue" hasta las típicas "descargas" de artículos de dudosa procedencia. Estos cuerpos extraños, por no decir cancerígenos, infectan el espinazo dantesco de la red, desde sus inverosímiles informaciones, que escurren como grifos por sus "ciberacueductos" artificiales, que invoca el ser humano desde la tarea "trascendental" de pulsar un clic.

Seducir y desmantelar son dos consignas maquiavélicas que emergen de las mazmorras de la web para, de alguna forma o peripecia, atrapar en sus telarañas virtuales a un prolífico número de adeptos, quienes, aturdidos, navegan sin brújula en las agitadas aguas de la red. Estos náufragos digitales, mal llamados, con un neologismo anglosajón, "cibernautas", son los encargados de desafiar las barreras físicas y acortar distancias para elaborar el primer volumen de la novela: "Recetario para esclerosis de pensamiento", novela que, sin duda alguna, venderá miles de ejemplares más que los que otrora vendió J. R. R. Tolkien con su saga El señor de los anillos. Cibernautas, me pregunto, palabra pegajosa que, de por sí, desborda la idea de navegantes, una especie de capitanes que surfean en los océanos de la información desde el timón del teclado. - ¡Vaya paradoja saber que se necesita ser todo un atleta náutico para poder sumergirse al fondo denso y oscuro de la web! - . Aunque, al pensarlo bien, los cibernautas no serían sino una expresión sublime de la "metaestupidez": un nivel superior de la ignorancia, donde generalmente se requieren más de dos años de estudio en redes sociales, Reality Show, farándula y narconovelas, para llegar al anhelado pensamiento gelatinoso, que originaría, por añadidura, una sintomatología excepcional, característica de estas sociedades digitales heridas de adrenalina y velocidad, que se denominaría: "telepatética"; es decir, patetismo y ridiculez a distancia, que se ve proyectado en la trivialidad de la web.

Pero ¿qué le vamos a hacer, si cada vez más el idioma se vuelve eufemístico, una especie de juglar que camina vendado sobre la cuerda floja que templan los mercados? Solo basta recordar, por ejemplo, que, en Colombia, no se asesina, sino se desaparece; no se secuestra, sino se habla de prisioneros de guerra; no hay corrupción administrativa, sino carruseles de contratación; no hay miseria, 
sino condiciones precarias de vida, etc. Y es precisamente, en este chiquero informático, en ese lupanar llamado "web 2.0",1 con el que la mayoría de sujetos metaestúpidos se acuesta, que paulatinamente las casas de cita, que antaño se llamaba biblioteca, van mutando y, de paso, se clausuran como tales, a tal punto de adaptarse a las exigencias del convulsionado siglo XXI que las convertirte, de golpe, en espacios virtuales de aprendizaje que revelan la expresión más exacerbada de la colonización digital.

Este boom de educación conectada conlleva inevitablemente pensar en el rol de la escuela en tiempos de redes, en los que el aprendizaje, así como la pangea del conocimiento, se disemina de manera viral por los ángulos de las pantallas de coltane que pretenden tomar por asalto y sin orden de cateo los lúgubres aposentos, ya sea con cuerpos anoréxicos en forma de Led, Full Hd, o Smart Tv, o ya sea a través de teléfonos inteligentes inundados de tantalio. A ello se le deben sumar las características del temerario tiempo presente, que desborda su libido a flor de piel para dar luz verde al nacimiento de la razón instrumental expresa en la trilogía: velocidad, inmediatez y minituarización. La imago mundi (imagen del mundo) que revela el escáner postmoderno es de una cerca que, metafóricamente, encierra el mundo desde sus safaris tecnológicos liderados por las tropas de la era de la información, lo que, a su vez, afecta en una reacción en cadena la médula misma de los antros de saber, así como el tejido social en general, al ser estos dos últimos sectores los más vulnerables a su agreste accionar. Sin embargo, resulta portentoso saber que estas guerras digitales, a las que se alude, son la principal competencia de futuro debido a las jugosas ganancias, derivadas de sus ordenadores, artefactos electrónicos y paquetes de software, que insisten hasta la náusea en el desarrollo de competencias laborales y no para la vida, hecho que, a su vez, ha generado una pérdida sistemática de valor frente a las tendencias educativas emergentes que circulan con gran afluencia sobre los márgenes seudocientíficos que pretenden auspiciar una interdisciplinariedad trasnochada, en lo que se dará en llamar educación del futuro o pedagogía tres mil².

1. La expresión web 2.0 se refiere al fenómeno masivo que ha suscitado el uso de Internet en las diferentes esferas sociales que hilvanan la cultura, que consiste en crear realidades virtuales que permiten interactuar entre sujetos y, así, conformar ciertas comunidades intangibles de comunicación, que se conocen como redes sociales, las que, a su vez, han sugerido ventajas en la educación, las investigaciones, el contacto entre personas a la distancia y el acceso ilimitado a la información, pero, contrariamente, también han suscitado patologías entre sus adeptos. Debido a la tarea "trascendental" de pulsar un clic desde el ratón, el usuario de Internet puede acceder a un universo vasto de conocimientos, que ofrece la caja de Pandora de la web 2.0. En la actualidad, se convive con los nuevos medios de comunicación que, cada día, generan más y más avances en materia de tecnología, a la par que surgen cada vez más artefactos, que permiten acceder a un mundo virtual, desde el que se maneja gran parte de una cultura global, que gana terreno debido a su popularidad, pero esto implica, también, la otra cara de la moneda: estos medios no solo ofrecen ventajas para el género humano, sino fomentan la exclusión y pérdida de aquellos que se encuentran fuera del sistema de comunicación digital y los segrega la sociedad red.

2. Al decir de Noemi Paymal (2008), autora del controvertido libro: Pedagogía 3000, se constituye en un modelo pedagógico poco ortodoxo, que va de la mano con los cambios culturales, científicos y tecnológicos introducidos en el marco del tercenio. Por tanto, lo que ella denomina pedagogía 3000 remite a un referente pedagógico sistémico y en expansión, que advierte sobre las tipologías de 
En consecuencia, y como bien señala la mirada lúcida de Castell, "Nuestras sociedades - postmodernas - se estructuran cada vez más en torno a una oposición bipolar entre la red y el yo", en la que es posible entrever una clara afinidad entre el hombre y la máquina, que acrecienta el ideal del Frankenstein tecnológico moderno, de aquel homo tecnologicus cargado de una alta dosis de insensibilidad. Dicho cometido no es descabellado, mucho menos descontextualizado de la realidad, a sabiendas de que un sinnúmero de actividades cotidianas se encuentran atravesadas por las tecnologías de la información y la comunicación que, además de alivianar labores y facilitarlas, generan la antinomia de la dependencia, así como trastornos y ansiedades derivadas del mal uso de lo que aquí se denominaría ideología cyborg. Dicha tendencia moderna se vale de los argumentos de la hibridación cultural para crear hombres máquinas, perfilados, en estos tiempos gaseosos, como el demiurgo de época, debido a la afluencia de feligreses que le rinden tributo, así como a sus estrategias tecnológicas de desinhibición, las que utilizan para tratar de mitigar la soledad acrecentada que experimentan actualmente las subculturas, que hallan en las aristas de la filosofía cyborg la alquimia para prolongar su espectral existencia. Tal ha sido el caso de las redes sociales, junto con la Internet inalámbrica, que han logrado remplazar la figura materna o paterna desde la fabricación de familias tecnológicas sustitutas, horneados por las espectrografías de la televisión o, en su defecto, por el estrambótico Wi-Fi de una casa.

En esta condición, que bien se podría traducir, para este interés particular de estudio, como esquizofrenia estructural entre función y significado, las pautas de comunicación social cada vez se someten a una tensión mayor, en la que se pone en entredicho la continuidad de la tradición oral, pero, contrariamente, se da vía libre al auge de la glocalización, que reitera, con gran eco, la idea de pensar global y actuar local, hecho que, a su vez, remueve sigilosamente la carga de la memoria histórica y cultural de los pueblos primigenios, junto con su sentido de pertenencia, para apostarle sin escrúpulos a la exportación del conocimiento a cambio del olvido de lo que se etiquetó bajo el nombre de tradición oral, sustrato del pensamiento anticolonial agrupado en las llamadas epistemologías del sur, al decir de Boaventura de Sousa (2009).

estudiantes fabricados en los telares del tercer milenio, sus inteligencias múltiples, ritmos y estilos de aprendizaje, junto con percepciones extrasensoriales, entre otras. El contenido del texto ha generado polémica en la opinión científica, que ve con escepticismo su singular filosofía. Sin embargo, más allá de la problematización de hipótesis o teoría, procedimiento pedagógico o cualquier modelo fijo de aprendizaje, la pedagogía tres mil se perfila como una constante apertura por entender y atender a las necesidades de los alumnos del futuro, quienes son, desde luego, bastante diferentes a las generaciones anteriores y, por ende, versátiles según las características del contexto en el que se encuentren inmersos. Al decir de esta autora, "la enseñanza se debe basar en lo visual y en el movimiento más que en lo verbal. En incentivar actividades ligadas a la creatividad, la imaginación y lo artístico. En dejarles que hagan varias tareas a la vez (está en su naturaleza). En proponerles ejercicios que desarrollen la intuición y el pensamiento ráfaga o flash (extremadamente rápido). En educarles en la contención, no en los límites". 
Se asiste hoy en día no solo a la era de la información, sino, además, a la era de la estupidez, desde donde es posible observar el debut del capitalismo académico, que conspira a favor de la cibercultura ${ }^{3}$. Por su parte, los mass-media - bombas electrónicas de distracción masiva- centran cada vez más su atención en producir los aspectos más fútiles de la vida a partir de un teatro de lo absurdo, en el que la imbecilidad televisiva triunfa por sobre la pedagogía crítica. Muestra de ello son los reality show, junto con el arsenal ideológico que dispara a quemarropa la majadería televisiva que insiste en transportar el acontecimiento educativo presencial y público al terreno virtual dominado por la cultura de la imagen que yergue al siglo XXI.

Empero, sería un desatino generalizar este efecto esclerótico de pensamiento suscitado por las máquinas de visión o considerarlas como el chivo expiatorio de la decadencia mental que padecen las instituciones educativas, a sabiendas de que hay algunos programas televisivos que someten el melodrama informativo a la lupa de la lectura crítica. Sin embargo, se sigue siendo esclavos de las lógicas mercantiles que hechizan desde sus frivolidades y llevan a que la persona se apegue al tener antes que al saber, a la información súbita y tergiversada por sobre la formación pausada; en últimas, se valen de su erótica consumista para lograr que se enamorara de forma compulsiva por la oferta y la demanda, por comprar en los supermercados e inaugurar preguntas existenciales frente al mostrador de cosméticos, que paradójicamente no ofrece nada. A la par de esta frívola, pero letal tarea, que parece cosificar a los rediles mercantiles, emerge el incontrolable impulso de "googlear", en el que, para hablar metafóricamente, se intima de manera promiscua con la cultura digital para hacer apología a la inteligencia artificial, que arranca de raíz todo indicio de subjetividad.

Ha sido el mundo de los ordenadores, junto con sus safaris tecnológicos, el encargado de causar una licuefacción educativa y, de paso, desviar el norte del conocimiento, para hacer de la escuela (colegio y universidad) un agregado más del rebaño digital; por tanto, una propiedad privada que es posible subastar al mejor postor del mercado neoliberal. De otra parte, los gobiernos, manejados por empresarios sin visión democrática, científica e intelectual, se convierten en el demiurgo de época, que los proletarios esperan defender para mitigar el malestar

3. En el relato digital se encuentra inmersa la denominada cibercultura, neologismo que designa la nueva forma de organización cultural, donde el uso de las nuevas tecnologías forma parte del propio modo de vida. Cabe agregar al respecto de la "cibercultura", que agrupa una serie de fenómenos culturales contemporáneos ligados principalmente al profundo impacto que han venido ejerciendo las tecnologías digitales de la información y la comunicación sobre aspectos tales como la realidad, el espacio, el tiempo, el hombre mismo y sus relaciones sociales, por tanto, sobre su química y su física como tales. Autores como Derrick de Kerckhove y Pierre Lévy conceptualizan su modus operandi y definen a la cibercultura como la tercera era de la comunicación, en la que se habría configurado un lenguaje todavía más universal que el alfabeto: el lenguaje digital; una era que habría seguido a las de la oralidad y la escritura. Por su parte, Kerkchove sostiene que el alcance e incidencia de la cibercultura opera desde la interactividad, la hipertextualidad y la conectividad, que conducen a pensar en una sociedad plagada de inteligencias en red. Desde el punto de vista del impacto tecnológico, resulta imprescindible discernir de qué modo están afectando las nuevas tecnologías a la inteligencia y a las formas de usarla. 
cultural que experimenta el mundo postmoderno. Paulatinamente, el imperio digital va ganado terreno desde su plan de mercadeo, que insiste en subvertir la importancia de leer por la de dejar de pensar y, así, vestir el atuendo que arropa la idiotez mediática. Las personas se relajan en los campos de concentración que ofrece la tecnología, junto a los extravagantes laberintos que ofrecen los centros comerciales, que, además de ejercer un bio-poder sobre la sociedad teledirigida, inauguran a la par una nueva modalidad de secuestro desde la comodidad de sus inteligentes hormigones.

Se sucumbe ante los destellos de luz que disemina, cual espejo, la tormenta eléctrica de las pantallas, para ceder, finalmente, a los embrujos del síndrome de "Whatsappitis" y "Facebookitis" que llevan a centrar los ojos sobre el lomo de una anoréxica pantalla y los dedos en el agujero negro de una caja idiota equipada con 4G o Android. La euforia mediática acecha, junto con el síndrome del ojo electrónico ${ }^{4}$ que vigila y castiga desde su panóptico sui géneris, para traspasar los límites de la intimidad de los frágiles aposentos, todo ello producto de la felicidad paradójica que ofrece la era de la información, perfilada actualmente como el Mesías de época encargado de predicar una nueva religión, cuya lógica consiste en transportar la vida orgánica al campo de la realidad virtual. De otra parte, la cultura postmoderna se empeña insistentemente en celebrar el Fin de la Historia y, en cierta medida, el fin de la razón, que otrora unían los grandes relatos entreverados en las fibras de la memoria. Como bien afirma Eco (2016):

"La televisión ha promovido al tonto del pueblo, con respecto al cual el espectador se siente superior. El drama de internet es que ha promocionado al tonto del pueblo al nivel de portador de la verdad". - Por tanto, resta suponer que el enjambre de las redes sociales va otorgando el derecho de hablar a legiones de idiotas que primero hablaban solos en el bar, después de un vaso de vino, sin dañar a la comunidad. Ellos eran silenciados rápidamente y ahora tienen el mismo derecho a hablar que un premio Nobel. Es la invasión de los idiotas.

La asunción implícita que profesa esta época del vacío - sutilmente llamada postmoderna - es la aceptación de la plena individualización de la conducta, la indiferencia relajada, el sincretismo cultural, el inmanentismo y el desborde de pasiones que transitan libremente sobre el gélido lomo de la nueva era. Dicho duelo de identidad y nostalgia de futuro que se imbrican en esta época, contagian en

4. Desde una apreciación personal y, al seguir la mirada lúcida de Umberto Eco, que acuña la expresión, el "síndrome del ojo electrónico" es la obsesión enfermiza de la ciudad por vigilar los zoológicos urbanos y allanar su intimidad desde sus formas varias de cíclopes digitales que monitorean el mundo. Por tanto, los cíclopes unidimensionales, como teléfonos celulares inteligentes, cámaras o cualquier otro dispositivo nanotecnológico capaz de grabar y compartir en tiempo real, hacen parte del arsenal ideológico del síndrome del ojo electrónico que, debido a su afluencia desmesurada, está ocasionando la comercialización de la vida, junto a la pérdida de la intimidad; entre otras cosas, influye considerablemente en la pérdida de la memoria cerebral, cuando se captan los momentos y experiencias vividas, las archivan y guardan en nuestros recuerdos, para darle paso a la memoria de un dispositivo. Como bien señala el autor: "No sé si los jóvenes actuales tendrán las mismas oportunidades que yo de madurar al llegar a la edad adulta. Para no hablar de todos los adultos que, con los ojos pegados a sus teléfonos celulares, ya se han perdido para siempre". 
efecto dominó el escenario educativo, que ofrece un mosaico variado de tendencias pedagógicas cargadas de una elevada dosis de virtualidad. Detrás de esta paleta educativa tiznada de sazones y desaciertos, se encuentran, también, identidades docentes con colores definidos y otros difuminados, que oscilan cual péndulo en los límites de la modernidad y postmodernidad educativa. Ello da pie para intuir que en las pasarelas de la era digital predomina un pluralismo pedagógico que bien se podría llamar hibridación educativa, constituida por mestizajes que combinan tanto aspectos tradicionales como innovadores, puntos de anclaje y disertaciones, impregnados muchas veces de forrajes educativos flotantes, tonalidades líquidas y matices variables, característicos de la actual escuela teledirigida.

Muestra de este coctel curricular son las tendencias educativas holísticas, que emergen de la mano de la llamada pedagogía tres mil, que articula en sinergia los enfoques por competencias, las pruebas estandarizadas, la neurociencia y la $\mathrm{New}$ Age como principal forma de evaluación, en que el aprendizaje por proyectos, los sistemas de gestión de la calidad o el agrupamiento por niveles de rendimiento (streaming) se convierten en la respuesta a la incógnita de cómo será la educación del futuro, todo, a la vez, justificado con un discurso tecnócrata y neoliberal que re-acentúa la antinomia pedagógica expresa en la idea de la escuela competitiva pero inclusiva, democrática pero profesional y otras dualidades desconcertantes, que se desbordan por añadidura en el corpus educativo. En este sentido, el saber y poder tradicional que porta el tranvía de la escuela se entrevera con nuevos enfoques y estrategias postmodernas, que inauguran una pugna de época, donde lo antiguo no acaba de morir, sino, por el contrario, queda reforzado, y lo nuevo se convierte en el pretexto perfecto para incorporar las bases de la filosofía cyborg u ontología 2.0,5 confabulada ideológicamente con la aldea global, que pretende tomar por asalto al mundo educativo. A la par de esta filosofía sui generis emerge la cibercultura de Pierre Levy (2007), en la que es posible encontrar prolíficos avances científicos y tecnológicos que van esculpiendo el relieve de la cultura, a tal punto de suscitar en sí una metamorfosis.

Todo indica que hoy en día predomina el imperio de las máquinas de visión, que pretenden cercar el mundo desde su pensamiento unidimensional para desplazar la educación presencial al terreno virtual y hacer de la vida orgánica un asunto plástico o sintético. En todo caso, la tecnología de la educación no es neutra, mucho menos inocua, como se podría suponer. La versatilidad humana, junto con la plasticidad neuronal, ha hecho que se debiera adaptar la "maquinaria"

5. La expresión web 2.0 se refiere a la actual característica de la Internet y su cometido de lograr la virtual interacción entre los sujetos, para así formar ciertas comunidades intangibles de interacción, estas últimas mejor conocidas como redes sociales que, en varios sentidos, han sugerido ventajas en la educación, las investigaciones, el contacto entre personas a la distancia y el acceso ilimitado a la información, además de brindar la posibilidad de organización entre algunos grupos para defender ciertas ideas y derechos. Todo tipo de manifestación es posible de compartir a través de la web 2.0 e incluso traspasar sus límites e internarse en el fondo denso de la deep web; es decir, de aquella parte de la red que contiene material, información y páginas web inéditas, que no están indizadas en ninguno de los buscadores existentes. 
intelectual a los nuevos modos e interfaces en los que las personas se relacionan con la información, lo cual permite pensar en una nueva modalidad de darwinismo social, que bien se podría denominar, para este interés particular, darwinismo tecnológico, donde el sujeto más apto prevalece en el ambiente virtual de aprendizaje, debido a su capacidad de adaptación a las exigencias del hábitat digital.

Esta facultad le permitirá al nativo digital sobrevivir en el medio y, por ende, garantizar su subsistencia en las condiciones impuestas por el canon de la sociedad red. Dicha afirmación no resulta desatinada a sabiendas de que existen evidencias empíricas que muestran que la adaptación a la llamada era digital es vertiginosa; en consecuencia, transitoria. Si antes se leía en papel, para hacer un tributo a la cultura moderna, ahora se lee en pantallas bulímicas, que hacen apología a la era de la información, en la que los prolíficos usuarios de la cultura digital tienden a volverse estúpidos por la abundancia y secuencias variadas en las que se presenta la caja de Pandora de la información, lo que, a su vez, reduce significativamente la capacidad de asombro y extrañeza, concentración, discernimiento y, por supuesto, posición escéptica o cuestionadora frente a lo que se presenta como aparentemente verdadero o real. Por tanto, no resulta descabellado afirmar que se asiste hoy en día a la época del docente espectral y el advenimiento de la sociedad de los idiotas.

En este sentido, los medios de comunicación, en conspiración con los objetos virtuales de aprendizaje, se presentan como señuelos ideológicos de naturaleza antieducativa, que cortejan el pensamiento lineal. Sin embargo, sería un desatino generalizar esta apreciación si se reconoce que, por lo menos, en el país de las bellas paradojas y el síndrome del avión -Colombia-, hay evidencias de programas educativos que subsisten entre los escombros del mercantilismo televisivo, entre los cuales es posible registrar a "contravía", "los puros criollos", "el profesor súper 0", "café picante", los ya desaparecidos "especiales Pirry", etc., tan solo por citar algunos ejemplos, que sobreviven en medio de un círculo de ahogamiento ejercido por los monopolios televisivos al servicio de las fuerzas oscuras del Estado, quienes pretenden amilanar el pensamiento desde estereotipos alienantes, como las narconovelas y patéticos reality show disparados a quemarropa desde el arsenal bélico de "paracol" y "exagerarcn".

De otra parte, existen evidencias neurobiológicas que demuestran cómo las conexiones neuronales, así como el cerebro reptil, responden a los estímulos informativos externos y como el cerebro se torna cada vez más plástico de lo que se pensaba; por tanto, más sensible a los cambios y estímulos suscitados en el afuera. Ello sirve de referencia para inferir que la experiencia de realidad aumentada recibida por los compulsivos usuarios de la web, muchos de ellos bloggers, $^{6}$ ha hecho que perdieran de manera significativa su capacidad para leer

6. Un blogger, también conocido con el nombre de bloguero, designa al autor de un blog electrónico, otrora llamado bitácora; es decir, una página web a modo de diario, en la que se publican artículos de diversa índole de manera periódica y ordenados cronológicamente, con el fin de ganar adeptos digitales a través de sus excéntricas publicaciones. 
textos extensos, por el mismo hecho de adaptarse a un consumo rápido y masivo de contenidos breves, que transitan libremente por las avenidas de la web 2.0, lo que, a su vez, permite concluir que el modelo antropocéntrico que otrora rigió a la modernidad tardía se diluye cual rostro en los límites de la arena, para dar paso al talante tecnológico donde se entroniza la filosofía "Google-céntrica" como paradigma de época.

Como bien señala Alan Quezada Figueroa (2014), en su ponencia "La era del homo tecnologicus y la ontología 2.0 ", 7 al respecto de este informacionismo global que,

En tanto que podemos hablar de una existencia digital, a través de las redes sociales y de los mencionados injertos digitales también, es preciso pensar en una inexistencia digital, a través de la que podemos pensar a aquellos que no tienen los recursos para formar parte de esta llamada "era digital", a quienes no pueden ser en esta era y además hemos de pensar en la muerte digital, aquellos que existieron digitalizadamente, pero no pudieron avanzar a la par de los descubrimientos tecnológicos, quedando así fuera en una suerte de muerte ante el nuevo sistema-mundo digitalizado, pues no hemos de olvidar que la tecnología avanza a pasos agigantados entre los que aplasta a los más frágiles.

Esta apreciación invita a repensar el dominio de las redes sociales y demás artilugios digitales desde una pedagogía crítica, o pensamiento del afuera, capaz de evocar su contracara y consiguientes objetos de seducción y demanda, de tal suerte que este ejercicio de disertación permita derribar las cercas que traza la indefensión aprendida ${ }^{8}$ al interior de la escuela para reconocer las tecnologías de la educación como un medio y no un fin en sí mismo.

Falsar al estilo popperiano el imperio digital es una tarea de cuño que compromete como tal a la comunidad educativa, en la que tanto docentes, padres de familia, estudiantes, directivos y sector productivo deben asumir una lectura crítica del fenómeno en curso y así desmantelar el cometido de la era de la información, ensañada actualmente en tomar por asalto el mundo desde

7. Ponencia presentada dentro de las actividades de las XXI Jornadas Filosóficas Ricardo José Avilez Espejel, realizadas en la Facultad de Filosofía y Letras de la Universidad Autónoma de Tlaxcala, 22 de agosto de 2014.

8. Uno de los problemas neurálgicos que enfrentan los docentes, en los márgenes de la educación postmoderna, consiste en dar cauce positivo a la indefensión aprendida. Al respecto de este concepto, cabe señalar que esta es una condición del ser humano que lo lleva a comportarse pasivamente, sin poder hacer nada ante situaciones reiteradas y sistemáticas de terrorismo psicológico que coaccionan al sujeto a bloquearse y actuar en contrario, debido a la interiorización inconsciente de la vigilancia, que lleva a que una persona aprendiera a permanecer pasiva ante las dificultades que se le presentan, por mínimas que sean. Si la escuela es, por definición, un organismo a favor del crecimiento, la formación y el desarrollo humano, resulta que muchas veces atenta contra ese crecimiento y desarrollo, pues, de un modo u otro, enseña a los estudiantes a aprender que nada pueden hacer ante algunas asignaturas o ante algunos docentes, que se vuelven un "coco"; es decir, la escuela los programa para aprender a "ser indefensos", a estar a merced de los docentes, de su voluntad, con lo que se pierde de manera irremediable su capacidad de autonomía, de creatividad, de respuesta inteligente ante las exigencias del entorno en el que viven. Esto se ve proyectado a la par en lo que se ha dado en llamar efecto Galatea o Pigmalión, en el que el discurso puede condicionar a favor o en contra a un determinado sujeto. 
su tecnofascinación. Hacer metacognición; es decir, repensar el mismo proceso tecnológico y su incidencia en el cerebro de la escuela permitirá dejar de concebir al éxodo digital como remedo de teología digital, para constituirse en una versión humanizada de la revolución tecnológica, y no en un Dios 2.0 que avala el nacimiento del ciberprofesor, capaz de intimar con la máquina y eliminar las barreras espacio-temporales que otrora distanciaban de la realidad.

Urge replantear la estrategia educativa y diseccionar con lupa la anatomía y arquitectura tecnológica masificada al servicio de la aldea global. Si se discurre, por ejemplo, al respecto del talante tecnológico, resulta inevitable pensar en la creación de una cátedra transversal suscitada al interior de los currículos de la escuela, en la que se posibilitara problematizar la afluencia de las TIC en los procesos de formación académica y decodificar los señuelos ideológicos, que ensanchan su oferta académica y consiguiente neuromarketing educativo, que afectan no solo a los profesores -especie en vía de extinción-, sino, además, al tejido social adepto, víctima de una histeria colectiva producida por una psicología a la inversa, que hace de los antros del saber escuelas en redes a la par que empresa lucrativa teledirigida por el canon de los cíclopes unidimensionales.

Queda al descubierto una nueva amenaza educativa latente en el surgimiento del ciberprofesor o, mejor aún, homo videns 2.0, que toma vida desde el vientre del e-learning, o formación electrónica, tal y como afirma McLuhan (1995), quien sostiene al respecto que:
Ahora todos vivimos en este mundo irracional, instantáneo, inmediato. Yo llamé a esto antes la aldea global, pero la gente pensó que esto era un ideal, que yo estaba imaginando una situación ideal. En realidad, una aldea no es una cosa ideal, porque la gente sabe demasiado acerca de los demás. No hay privacidad, no hay identidad. En la aldea global eléctrica la gente sabe demasiado, y ya no hay lugar donde esconderse.

Y es precisamente en las fauces de la aldea global donde emerge la ciudad tecnológica, o ciberciudad, que comienza a reorganizarse, a acomodarse como tal al orden digital que insiste en transponer semánticamente la naturaleza viviente por la cosmética, lo trascendental por lo trivial; por tanto, lo presencial por lo virtual. Esta ráfaga de información ligera y distorsionada, que transita en las autopistas de los medios masivos de comunicación, hace que la sociedad postmoderna, en la que se está insertos, se encuentre fragmentada y globalizada; por tanto, mediada por nuevos integrantes de la familia nuclear, que bien se podría llamar familia virtual, como Facebook, Twitter, y whatsapp, que muestran el narcicismo del homo tecnologicus, así como su versatilidad social para conformar nuevos clanes virtuales e incluso inaugurar nuevas parafilias, como el tecnosexualismo, que se caracteriza por la atracción hacia los robots, hacia los fetiches humanoides, máquinas o cualquier especie de aparato con inteligencia artificial. Finalmente, en este espacio intangible (ciberespacio), el cuerpo adquiere una nueva dimensión: la del cuerpo virtual.

Al respecto, McLuhan (1995) sostiene que los efectos de los medios son nuevos ambientes de aprendizaje que, a su vez, son una reprogramación de la vida 
sensorial. Según su parecer, no puede haber ningún cambio tecnológico o físico en los medios de intercomunicación que no se acompañase por un espectacular cambio social, ya que la nueva tecnología "sacude" literalmente a la sociedad actual desde su base como si se tratase de un proceso de derretimiento social. En efecto, la sociedad red que embiste al corpus educativo crea un cerebro sin órganos, que se reduce a la simple labor de pulsar un clic desde el anonimato que ofrece el campo de concentración de un Wi-Fi de una alcoba.

De igual forma, el mundo globalizado, hipercomunicado, hace que la educación presencial padezca una transposición teleológica, para dar paso al nacimiento de la era del envase y la masificación de la información.

Cifras alarmantes corroboran con fuerza la afinidad del hombre postmoderno con la cultura digital. Según el informe presentado por el Ministerio de TIC en Colombia, al finalizar el primer trimestre de 2016, el número total de conexiones a Internet de Banda Ancha alcanzó los 13.233 .368 accesos en el país, mientras las demás conexiones a Internet sumaron 473.783, para un agregado nacional de 13.707.151 conexiones. Por su parte, el uso de telefonía celular, al término del primer trimestre de 2016, al decir de este Ministerio, alcanzó un total de 57.292.621 usuarios en Colombia, para presentar un aumento de un punto porcentual en relación con el índice de penetración del mismo trimestre del año anterior, que se ubicó en el 116,5\%.

Como se puede observar, el interés cuasi patológico de acceder al mundo digital lleva a que el uso de la tecnología móvil aumente de manera exponencial en el mundo, y en particular en Colombia, a tal punto de convertir a este fenómeno en un asunto viral, que posiciona al país como uno de los mayores usuarios de telefonía móvil en Latinoamérica, connotación que, a su vez, ha hecho acreedora a Colombia como el país de los "Smartphone". Todo indica que se presencia hoy por hoy no solo un cambio de época, sino una época de cambios en los que predomina no solo la escuela teledirigida, y consecuente con un capitalismo cognitivo, sino, además, se asiste al clímax de una cultura light y maleable, tal y como lo había advertido Alvin Toffler (1990) en su controvertida obra El shock del futuro, en la que el sistema educativo y demás esferas de la cultura padecen traumatismos epistemológicos y axiológicos.

En este orden de ideas, y al seguir la mirada lúcida de Marco Raúl Mejía (2011), es posible sostener que:

Las nuevas realidades del conocimiento ubican a la escuela entre la premura de su afirmación, en una modernización que se fundamenta en el discurso hegemónico que se viene construyendo para ella desde los escenarios internacionales, dotándola de un discurso técnico-objetivo exento de intereses, apalancados en los tecnoburócratas nacionales, con lo que hace creer que esta es la única escuela posible.

A la luz de este nuevo orden mundial, que bien se podría denominar como capitalismo intelectual, la educación adquiere unas características diferentes a las de su modelo anterior (modernidad) y se dispone a migrar al estado gaseoso postmoderno. En esta nueva lógica de conocimiento desbordado e imperio de 
lo efímero, no es posible problematizar el acontecimiento educativo sin antes diseccionar, con el escalpelo de la filosofía de la sospecha, las arbitrariedades del mercado neoliberal, que insiste en la segregación social y la construcción de nuevos grupos sociales disímiles, como los infopobres, que acrecientan la exclusión y, paradójicamente, hinchan el ego de la sociedad red. Esta apreciación se ve ratificada por Jesús Martín-Barbero (1996) al respecto de la educomunicación, cuando sostiene que "Tenemos una televisión y aparatitos electrónicos bastardos que no se corresponden con la diversidad cultural de nuestras sociedades", precisamente porque excluyen la diversidad de las culturas populares segregadas por la elite digital.

Si algo puede insinuarse, a manera de cierre no determinante, es reiterar la necesidad de activar una pedagogía crítica en tiempos volátiles y líquidos como los estos; de no ser así, todo seguirá conspirando para que el entramado educativo latinoamericano se teledirigiera por el imperio digital y la empresa neoliberal, yuxtapuestos históricamente a la pedagogía del oprimido, que envuelve el alma de la educación popular.

\section{CONCLUSIONES}

La cultura digital que interviene en la educación está transformando vertiginosamente las formas de producción y reproducción de la cultura en los espacios escolares universitarios y en otros espacios públicos y privados, con los cuales interactúan los académicos y alumnos, lo que genera la necesidad de reformular el proceso educativo sobre nuevas bases epistemológicas y metodológicas, donde se aborden críticamente los viejos aprendizajes y se combinen con las nuevas formas educativas propias de la posmodernidad, en su versión progresista. Por ello, la educación, en el cometido de la era del conocimiento, debe considerarse un proceso democrático, en el que se prioricen los valores humanos y el pensamiento crítico, sin menospreciar los aspectos relacionados con la vinculación de la educación con los sistemas productivos y mercados de trabajo no alienantes.

Latinoamérica, en cuanto a materia educativa respecta, se encuentra impregnada de una moda y tendencia educativa posmoderna. En este orden de ideas, los modelos educativos latinoamericanos se encuentran desvinculados de la realidad social, al ser copias de paradigmas extranjeros marcados por lógicas europeas y teorías neoliberales norteamericanas que abogan por la transposición semántica del paradigma empresarial a la escuela pública. Por esta razón, es virtualmente inevitable huir de la hibridación cultural, la tercera ola, la cultura digital; el neoliberalismo, la era del conocimiento y la globalización. Sin embargo, los mal llamados países tercermundistas, o en vía de desarrollo, según el imaginario eurocéntrico, pueden retener el flujo de su identidad y dar largo aliento al tema educativo debido a la incorporación del enfoque glocal, opuesto al enfoque cosmopolita postmoderno. Sin un proceso de acomodación tecnológico, económico y globalizado, sin la reinvención del acto educativo, el docente, así como los epicentros de saber, tenderá a remplazarse por el influjo de la vitrina pantalla. 


\section{REFERENCIAS BIBLIOGRÁFICAS}

Castells, Manuel. 1999. La Era de la Información: Economía, Sociedad y Cultura: La sociedad Red. México: Siglo XXI.

_. 2002. La dimensión cultural de Internet. (julio). http://www.uoc.edu/culturaxxi/esp/a.

Lanier, Jaron. 2011. Contra el rebaño digital. Un manifiesto. México: Debate.

Lévy, Pierre. 2007. Cibercultura. La cultura de la sociedad digital. Barcelona: Anthropos.

Lipovetsky, Gilles. 2001. El imperio efímero de la moda. Barcelona: Anthropos.

_.2001. La era del vacío. Barcelona: Anthropos.

Marcuse, Herbert. 1969. El Hombre Unidimensional. Barcelona: Seix Barral.

Martín-Barbero, Jesús. 1996. De la ciudad mediada a la ciudad virtual. Telos 44 (dic.-feb.):15-21.

McLuhan, Marshall y B. R. Powers. 1995. La aldea global. Barcelona: Gedisa.

Mejía, Marco. 2011. Pensar la educación y la pedagogía en el siglo XXI. Tunja: Universidad Pedagógica y Tecnológica de Colombia.

Paymal, Noemí. 2008. Pedagogía 3000. Córdoba, Argentina: Editorial Brujas.

Sánchez Sánchez, María. 2016. “La invasión de los necios”: la opinión que tenía Umberto Eco de Internet y las redes sociales. https://verne.elpais.com/verne/2016/02/20/articulo/1455960987_547168.html

Santos, Boaventura de Sousa. 2009. Una epistemología del Sur. La reinvención del conocimiento y la emancipación social. México: Clacso/Siglo XXI.

Toffler, Alvin. 1990. El «shock» del futuro. Barcelona: Plaza \& Janés.

_. 1991. El cambio del poder. Barcelona: Plaza \& Janés.

Virilio, Paul. 1993. La máquina de visión. Madrid: Anthropos, 1993. 168 p.

—. 1997. El cibermundo, la política de lo peor. Madrid: Cátedra. 